\title{
Chemical LTD in the CA1 field of the hippocampus from young and mature rats
}

\author{
Amer Kamal, Geert M. J. Ramakers, Ivan J. A. Urban, Pierre N. E. De Graan and Willem Hendrik Gispen \\ Department of Medical Pharmacology, Rudolf Magnus Institute for Neurosciences, Utrecht University, PO Box 80040, 3508 TA, \\ Utrecht, the Netherlands
}

Keywords: development, hippocampus, long-term depression, NMDA, synaptic plasticity

\begin{abstract}
Within the hippocampal formation, two forms of long-lasting synaptic plasticity, long-term potentiation (LTP) and long-term depression (LTD), can be induced which require the activation of NMDA receptors. Interestingly, it has been shown that both LTP and LTD are reduced in adult animals. Recently, a new chemical protocol has been described which elicits LTD in the CA1 field of the hippocampus. Application of $20 \mu \mathrm{M}$ NMDA for $3 \mathrm{~min}$ results in a stable and long-lasting decrease in the evoked synaptic responses. We used this protocol to induce LTD in hippocampal slices from young and adult rats and show that this form of LTD is AP5-sensitive and can be blocked by the protein phosphatase inhibitor cyclosporin A in slices from adult animals. In contrast to electrical LTD (induced by prolonged low frequency stimulation), the extent of chemical LTD was not different between the young and adult rats. These findings indicate that the intracellular signal transduction cascades involved in long-lasting synaptic depression are still intact in adult animals.
\end{abstract}

\section{Introduction}

Glutamate, the main excitatory neurotransmitter in the brain, and its receptors have an important role in learning and memory. Glutamate receptors can be divided into metabotropic and ionotropic receptors, and the latter can be classified into three types according to the sensitivity to agonists, namely $N$-methyl-D-aspartate (NMDA), $\alpha$ amino-3-hydroxy-5-methyl-4-isoxazolepropionic acid (AMPA), and kainic acid receptors (Watkins \& Evans, 1981). The hippocampus is an area involved in learning and memory processes (Bliss \& Collingridge, 1993; Jarrad, 1995). Animal experiments have shown that NMDA receptors are important for several learning and memory processes (Morris etal., 1986; McHugh etal., 1996; Tsien etal., 1996). For example, treatment of rodents with NMDA blockers or antagonists impaired learning in various behavioural tasks (Mondadori etal., 1989; Morris etal., 1986; Danysz etal., 1988). In addition, experiments with NMDA knockout mice have shown the crucial role of these receptors in spatial learning (Wilson \& Tonegawa, 1997; McHugh etal., 1996; Tsien etal., 1996).

NMDA receptors in the hippocampus are also involved in longterm depression (LTD) and long-term potentiation (LTP) (see Bliss \& Collingridge, 1993; Bear \& Malenka, 1994; for reviews). Two major forms of long-lasting synaptic plasticity are LTD and LTP; they depend on the entry of $\mathrm{Ca}^{2+}$ ions into postsynaptic cells to activate the molecular transduction cascades that bring them about. Evidence suggests that the speed and amount of $\mathrm{Ca}^{2+}$ ions entering the cells determines whether potentiation or depression of synaptic activity occurs (Hansel etal., 1996, 1997; Cummings etal., 1996). We recently showed that prolonged low-frequency stimulation (LFS) could induce significant LTD in hippocampal slices taken from adult

Correspondence:Professor W. H. Gispen, as above.

E-mail: A. Kamal@med.uunl

Received 17 July 1998, revised 12 May 1999, accepted 25 May 1999 rats, although the depression was significantly less than that measured in slices from young rats (Kamal etal., 1998). Others reported that hippocampal slices from adult animals do not express significant LTD in response to LFS (Wexler \& Stanton, 1993; Bashir \& Collingridge, 1994; Errington et al., 1995; Wagner \& Alger, 1995), even though the same protocol can induce depotentiation of potentiated synapses in mature animals (Wagner \& Alger, 1995).

LTP is usually induced by short, high-frequency $(100-200 \mathrm{~Hz})$ stimulation of afferent fibres whereas LTD is induced by prolonged, low-frequency $(1-5 \mathrm{~Hz})$ stimulation of afferent fibres (Bliss \& Collingridge, 1993; Bear \& Malenka, 1994). Recently, Lee et al. (Lee etal., 1998) reported a chemical method of inducing LTD by which hippocampal slices are perfused with medium containing $20 \mu \mathrm{M}$ NMDA for $3 \mathrm{~min}$. Here we further characterize the properties of chemically (NMDA)-induced LTD and compare the extent of chemical and electrical LTD in slices from young (2-week-old) and adult (24-week-old) rats. We show that NMDA elicits LTD to a similar extent in slices from young and adult rats. The chemical LTD was blocked by the phosphatase 2B inhibitor cyclosporin A in slices from adult rats, whereas cyclosporin A did not affect chemical LTD induction in slices from young rats. Induction of chemical LTD occluded further induction of electrical LTD, indicating that the same signal transduction processes are involved. In summary, we show that NMDA induces equal amounts of LTD in hippocampal slices from young and from adult rats, suggesting that the intracellular signal transduction mechanisms leading to synaptic depression are still intact in adult animals.

\section{Methods}

Two-week-old (60-80 g, $n=13$ ) and 6-month-old (400-450 g, $n=13$ ) male Wistar rats were used. The rats were killed by decapitation after a short period of inhalation anaesthesia with Isoflurane (Abbott 
Laboratories Ltd, Hoofddorp, the Netherlands). The brains were rapidly removed and placed in ice-cold medium, and the hippocampi were dissected as described elsewhere (Biessels et al., 1996).Transverse $450 \mu \mathrm{m}$ thick slices from the medial hippocampus were cut and stored in an artificial cerebrospinal fluid (ACSF) of the following composition (in $\mathrm{mM}$ ): $\mathrm{NaCl}, 124 ; \mathrm{KCl}, 3.3 ; \mathrm{KH}_{2} \mathrm{PO}_{4}, 1.2$; $\mathrm{MgSO}_{4}, 1.3 ; \mathrm{CaCl}_{2}, 2.5 ; \mathrm{NaHCO}_{3}, 20$; and glucose, 10. After $1 \mathrm{~h}$ at room temperature, the slices were transferred to the recording chamber and perfused with ACSF at a rate of $2 \mathrm{~mL} / \mathrm{min}$ at $30^{\circ} \mathrm{C}$. Bipolar stainless steel electrodes of $100 \mu \mathrm{m}$ diameter were placed on the Schaffer collateral fibres as stimulation electrodes. Activity in the dendritic layer of the CA1 field in the stratum radiatum was recorded by using glass microelectrodes filled with ACSF $(3-5 \mu \mathrm{m}$ tip diameter; $0.5 \mathrm{M} \Omega$ ).

A stimulus-response curve was made by using five stimulus intensities (I1-I5) ranging from stimulus intensities evoking threshold responses (I1) to intensities eliciting maximal responses (I5). The stimulus intensity that evoked a half-maximum amplitude field excitatory post synaptic potential (fEPSP) was used for the remainder of the experiment. Only slices that showed fEPSP responses of $>1 \mathrm{mV}$ amplitude were used in the experiment. Stable baseline responses were recorded for at least 15 min with test stimuli given at a rate of $0.05 \mathrm{~Hz}$. Only those slices that showed a stable slope and amplitude were included in the experiment. The slopes of the baseline responses measured and subsequent responses expressed as a percentage of this baseline. Data were digitized by an A-to-D converter (Cambridge Electronic Design Ltd, UK) and transferred to an IBM-compatible computer. The Spike2 analysis program (Cambridge Electronic Design Ltd, UK) was used to calculate average fEPSP slopes every $5 \mathrm{~min}$

Chemical LTD was induced by perfusing the slices in the recording chamber with $20 \mu \mathrm{M}$ NMDA (Sigma, St Louis, USA; $20 \mu \mathrm{M}$, dissolved in ACSF) for $3 \mathrm{~min}$. The slices were not stimulated during this period. The medium was then changed to normal ACSF and the evoked fEPSPs were recorded for $60 \mathrm{~min}$.

Four types of experiments were performed to further characterize NMDA-induced LTD. To asses the ability of D,L-2-amino-phosphonovaleric acid (AP5; an NMDA receptor antagonist, Cambridge Research Biochemical, Norwich, UK, $50 \mu \mathrm{M}$, dissolved in ACSF) to inhibit the induction of LTD, two slices were perfused with a medium containing $50 \mu \mathrm{M}$ AP5 six minutes before and six minutes after NMDA. The evoked fEPSPs were then recorded after the medium was changed to the normal ACSF. The effect of phosphatase inhibitors on NMDA-induced LTD was tested by perfusing the slices with two types of phosphatases inhibitors, namely, cyclosporin A [Biomol Research Labs, Perth, Australia; $1 \mu \mathrm{M}$, dissolved in dimethylsulfoxide (DMSO), Merck, Darmstadt, Germany] and okadaic acid (Calbiochem, La Jolla, USA; $1 \mu \mathrm{M}$ ). The effect of perfusing the slices with $20 \mu \mathrm{M}$ NMDA for 1 min instead of 3 min was tested in three slices. The evoked fEPSPs were recorded for $60 \mathrm{~min}$ after the medium was changed to the normal ACSF. Finally, slices from rats from both age groups were used to test a possible interaction between electrical and chemical LTD. In one set of experiments, after baseline recordings for $15 \mathrm{~min}$, slices were first perfused with $20 \mu \mathrm{m}$ NMDA for $3 \mathrm{~min}$ and fEPSPs were recorded for $40 \mathrm{~min}$, and thereafter slices received LFS and fEPSPs were recorded for another $30 \mathrm{~min}$

The results are presented as means \pm SEM. Wilcoxon's matched pairs test was used to assess the significance of the decrease in the slopes of the fEPSPs before and $60 \mathrm{~min}$ after induction of LTD (electrical or chemical). Between-group differences in the slopes of the fEPSPs were assessed by using the ANOVA test.

\section{Results}

Perfusion of the slices with $20 \mu \mathrm{M}$ NMDA for 3 min initially caused a marked decrease in fEPSP slope in both age groups. The responses recovered slowly and progressively until a stable fEPSP slope about $59.2 \pm 5.4 \%$ of the baseline fEPSP slope was reached in slices from young animals, and $47.0 \pm 9.0 \%$ of the baseline fEPSP slope in slices from adult animals ( $P \leqslant 0.05, n=6$, for both age groups; Fig. 1A). One hour after perfusion with the NMDA-containing medium the decrease in the fEPSP slope was not statistically different between the two groups $(P \geqslant 0.1)$. Typical fEPSP traces are plotted in Fig. 1A.

Electrical LTD was induced by repeating a 15-min LFS protocol twice (separated by an interval of $15 \mathrm{~min}$ ). The fEPSP slopes were decreased significantly in both groups $(P \leqslant 0.05, n=6)$, but the reduction was less in the slices from the mature rats (Fig. 1B). Sixty minutes after LFS, the fEPSP slopes of the slices from adult animals (24-week) were decreased to $84.8 \pm 4.2 \%$ of the baseline slopes, while the slopes of the fEPSPs of the slices from 2-week-old rats were $62.5 \pm 3.4 \%$ of the baseline values $(P \leqslant 0.05)$.

The stimulus-response relationships in slices from young and adult rats were studied by measuring the slopes of the fEPSPs elicited by five gradually-increasing intensities of stimulation before and after the induction of chemical LTD. The stimulus-response curves before and after chemical LTD induction were significantly different

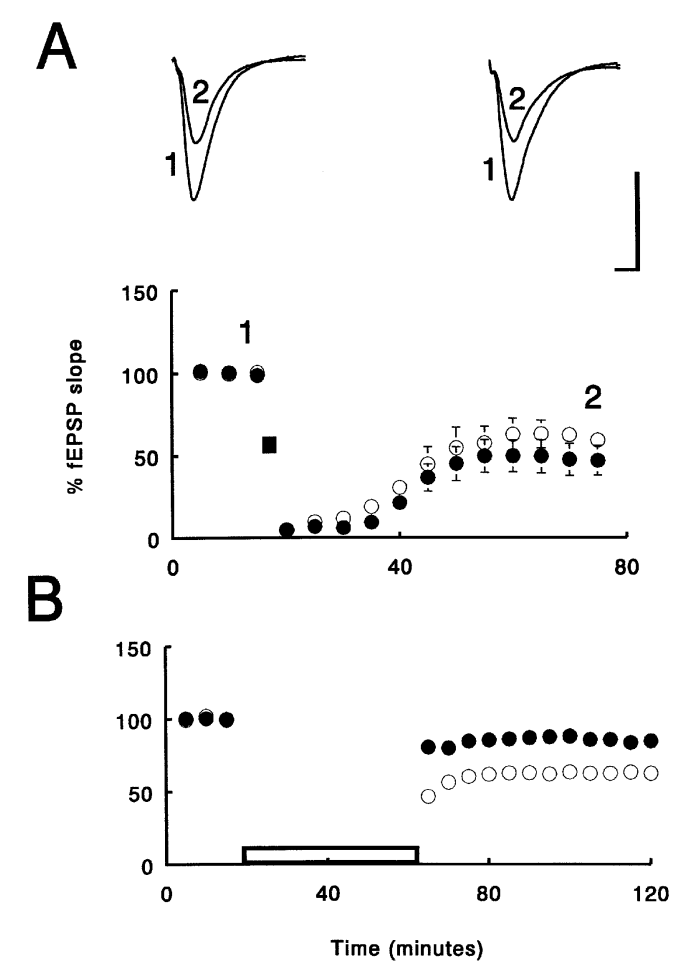

FIG. 1. Chemical and electrical LTD in slices from young and adult rats. Open circles, 2-week-old rats; filled circles, 6-month-old rats. (A) The chemical protocol to elicit LTD in hippocampal slices consisted of application of NMDA $(20 \mu \mathrm{M})$ for $3 \mathrm{~min}$ (solid bar). The fEPSPs were then recorded for $1 \mathrm{~h}$ after the medium was changed back to the NMDA-free ACSF. The error lines represent the SEM. Typical examples of responses of slices from both age groups are shown in the top. Each example is an average of 15 traces, before NMDA application (1) and $60 \mathrm{~min}$ after NMDA application (2). Calibration, $5 \mathrm{~ms}, 1 \mathrm{mV}$. (B) Electrical protocol to elicit LTD consisted of low frequency stimulation (LFS) of $1 \mathrm{~Hz}$ frequency for $15 \mathrm{~min}$ (repeated two times, separated by a $15 \mathrm{~min}$ interval; open horizontal bar). The amount of fEPSP depression was higher in slices from the young animals (to $62.5 \pm 3.4 \%$ ) than in slices from the adult animals $(84.8 \pm 4.2 \%)$. 
$(P \leqslant 0.05, n=6)$ irrespective of whether the slices were from young or adult rats (Fig. 2).

NMDA-induced LTD in slices from mature rats was prevented by AP5 $(50 \mu \mathrm{M})$, an NMDA-receptor antagonist (Fig. 3A). The fEPSP slope recorded at $60 \mathrm{~min}$ was $99.2 \%$ of baseline $(n=2)$. Furthermore, the stimulus-response relationship was the same before the application of NMDA and AP5 and 60 min later (Fig. 3A). Application of NMDA to slices from young rats for $1 \mathrm{~min}$ instead of 3 min resulted in a marked decrease in the slope of the fEPSP to levels approaching zero (although the fibre volley was not affected; see Fig. 3B) when the medium was changed to normal ACSF. Thereafter the slope of the fEPSP increased gradually to reach $112.9 \pm 5.9 \%(n=3)$ of baseline 60 min later. This indicates that NMDA should be applied for longer than 1 min to induce significant LTD.

Cyclosporin A $(1 \mu \mathrm{M})$, a powerful inhibitor of protein phosphatase 2B/calcineurin (Kunz \& Hall, 1993) which prevents electrical LTD (see, e.g., Mulkey etal., 1994), prevented the development of chemical LTD in slices from mature animals. The slope of fEPSPs during the baseline period and 40 min after perfusion with NMDA plus cyclosporin A were not significantly different $(103.3 \pm 10.2 \%$ at $40 \mathrm{~min}$ after application, $P \geqslant 0.1, n=4$; see Fig. 4A). Dimethylsulfoxide ( $0.1 \%$ final concentration) did not affect baseline responses and did not affect the induction of chemical LTD (not shown). Similar results were obtained with okadaic acid $(1 \mu \mathrm{M})$, an inhibitor of protein phosphatase 1 and $2 \mathrm{~A}$ in slices from adult animals (data not shown). In slices from young animals, cyclosporin A failed to block chemical LTD (Fig. 4B). NMDA application plus cyclosporin A resulted in a significant reduction of the slope of the fEPSP $(63.6 \pm 3.8 \%$ at $60 \mathrm{~min}$ after application, $P \leqslant 0.05, n=4)$. These
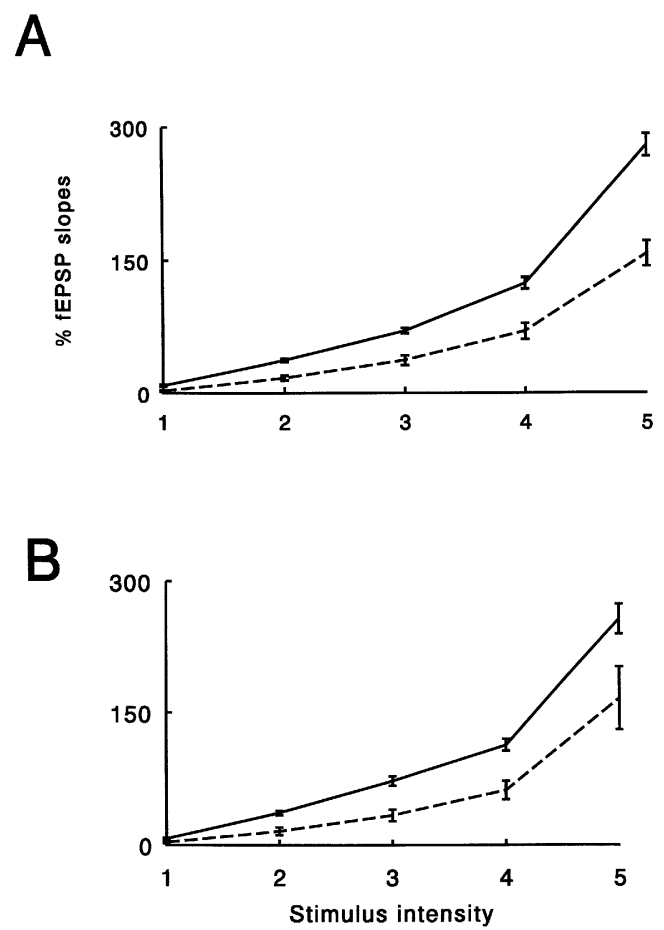

FIG. 2. Stimulus-response relationships before and after the chemical LTD in slices from young and adult rats. (A) Stimulus-response relationships showing the slope of the fEPSP in response to five different stimulation intensities ranging from threshold intensity to the intensity evoking maximum responses in slices from young animals. The responses were recorded twice, before the application of the chemical (NMDA) LTD protocol (solid lines), and after the end of the experiment (dotted lines). (B) As in A but in slices from adult animals. results show that chemical LTD in mature animals, like electrical LTD in young animals, requires the activation of protein phosphatases.

Both electrical and chemical LTD protocols significantly decreased the fEPSP slope in slices from young and adult rats (Fig. 2) although the electrical LTD protocol decreased the fEPSP slope less in slices from adult rats than in slices from young rats (Fig. 1B). To test whether chemical LTD occludes any further induction of electrical LTD, slices from young and mature animals were first perfused with medium containing $20 \mu \mathrm{M}$ NMDA for 3 min and then with normal ACSF, and the fEPSPs evoked were recorded for $40 \mathrm{~min}$. In both groups of slices, NMDA application caused depression of the responses to values of $46.6 \pm 2.5 \%$ and $47.1 \pm 3.1 \%$ of baseline, respectively $(P \leqslant 0.05 ; n=5$; see Fig. 5$)$. The slices were then stimulated with a train of LFS $(1 \mathrm{~Hz}$ for $15 \mathrm{~min})$ and the evoked fEPSPs were recorded for another $30 \mathrm{~min}$. No significant further depression of the synapses was seen in either groups of slices after 30 min of the LFS trains $(P \geqslant 0.1)$.

\section{Discussion}

The main finding of this study is that application of $20 \mu \mathrm{M}$ NMDA for three minutes induces a robust and long-lasting reduction in synaptic responses in the CA1 field of hippocampal slices of both young (2week-old) and adult (6-month-old) animals. This form of LTD (chemical LTD) is blocked by AP5 and occludes further induction of LTD by LFS. Surprisingly, chemical LTD in young slices is not blocked by cyclosporin A, whereas chemical LTD in adult slices is blocked by cyclosporin A.

We show that NMDA is equally effective in inducing LTD in hippocampal slices from young and from adult rats, whereas electrical stimulation was more effective in inducing LTD in slices from young rats than it was in slices from adult rats. The LTD induced by electrical stimulation was less pronounced than that induced by NMDA, and application of $20 \mu \mathrm{M}$ NMDA for 3 min might fully saturate the depression in slices from both young and adult (mature) rats, and thereby prevent any differences between the age groups being detected. The stimulation protocol $(1 \mathrm{~Hz}$ for $15 \mathrm{~min})$ which is effective in inducing electrical LTD in young rats is not equally effective in inducing such depressions of the synapses in the mature animals (Bashir \& Collingridge, 1994; Errington et al., 1995; Wagner \& Alger, 1995; Kamal etal., 1998). During development there is a change in NMDA receptor subunit composition and the expression of splice variants, which could be related to changes in synaptic plasticity (Paupard et al., 1997; Monyer et al., 1994; Dunah etal., 1996). Because NMDA receptors are essential for both LTP and LTD (see Bear \& Malenka, 1994; Bliss \& Collingridge, 1993 for reviews), the developmental changes in the expression of LTD and LTP may be a direct consequence of the developmental change in NMDA receptor configuration. Hippocampal synapses from adult rats are able to express LTP similarly to those from young rats, whereas the ability to express LTD was strongly diminished in synapses from adult rats compared with young rats (Kamal etal., 1998). This indicates that LTD has a specific threshold for changes in NMDA receptor functioning which is different from that for LTP. The fact that NMDA induces equal amounts of LTD in young and adult rats suggests that intracellular postsynaptic transduction mechanisms that lead to synaptic depression are still intact in adult animals.

The finding that cyclosporin A and okadaic acid inhibited the chemical LTD in adult animals (this study) and electrical LTD in young animals (Mulkey etal., 1993, 1994) shows the importance of the activation of protein phosphatases in LTD. The diminished LTD 
FIG. 3. Chemical LTD can be blocked by AP5 and is not induced by a short NMDA application. (A) NMDA $(20 \mu \mathrm{M})$ was applied for $3 \mathrm{~min}$ (solid bar) during perfusion of the slices with AP5 for 15 min (open bar). The inset shows typical examples of sweeps before and 60 min after NMDA application in the presence of AP5. After $60 \mathrm{~min}$, the slopes of the fEPSPs were not different from the slopes recorded at baseline. The stimulus-response relationships before and one hour after the application of AP5 + NMDA (lower graph) demonstrates no significant changes. (B) The upper graph demonstrates the effect of NMDA application for $1 \mathrm{~min}$ on the fEPSP in hippocampal slices. Immediately after NMDA application there was severe depression of synaptic activity (2), which gradually increased again. The responses after one hour (3) were not different from the baseline responses (1). Calibration, $5 \mathrm{~ms}, 1 \mathrm{mV}$.
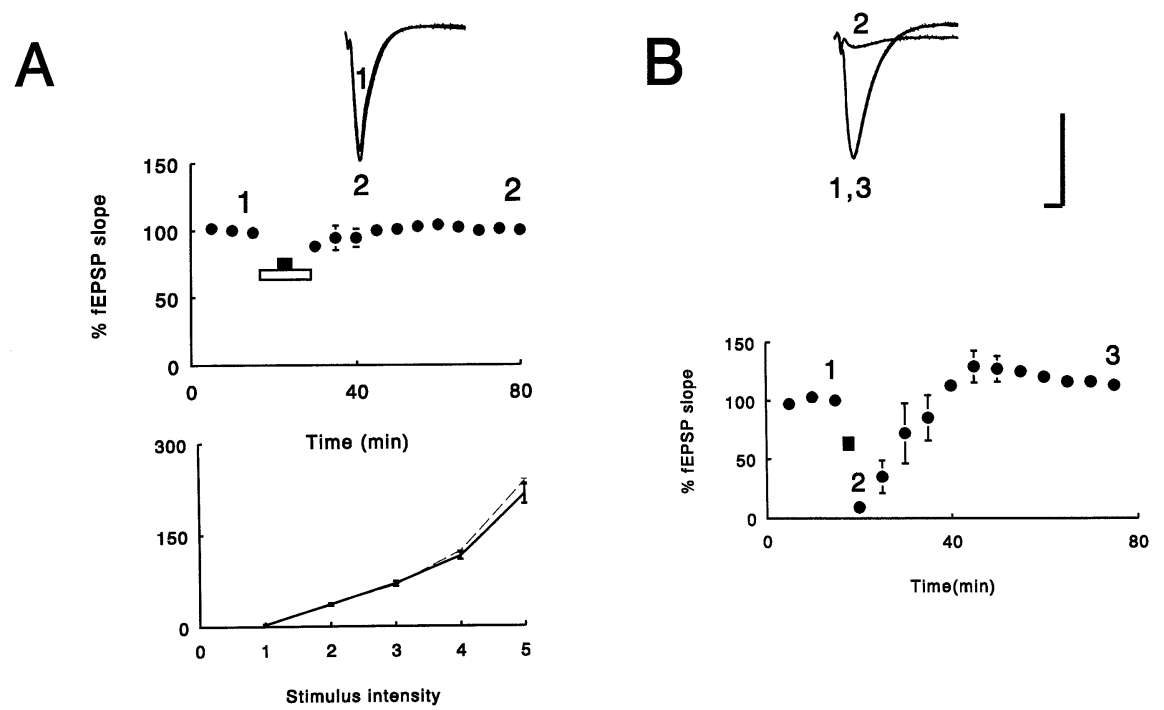

A

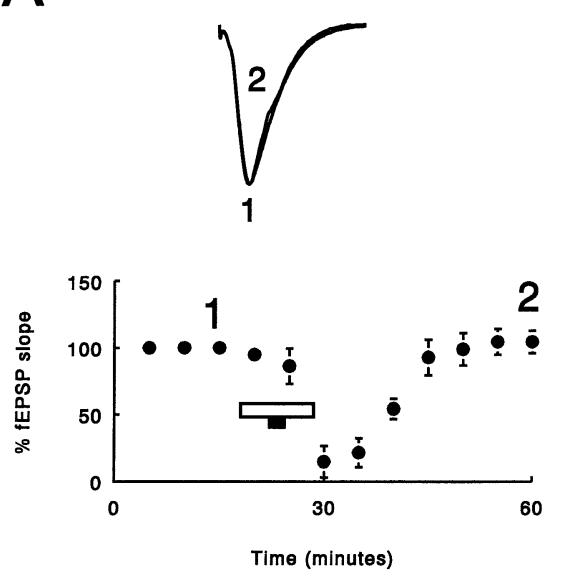

B
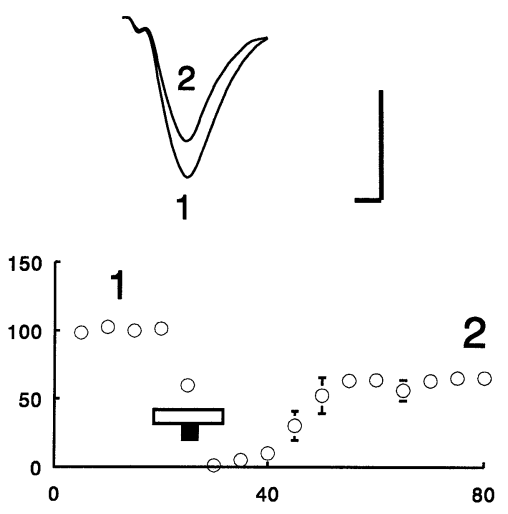

FIG. 4. Chemical LTD requires phosphatase activity in slices from adult animals, but not in slices from young animals. (A) The chemical LTD protocol (solid bar) was applied to slices from mature animals, during application of $1 \mu \mathrm{M}$ cyclosporin A (open bar). The response $40 \mathrm{~min}$ after the medium was changed to the standard ACSF (2) were similar to those at baseline (1). (B) The same experiment as in A, but in slices from young (2-week-old) animals. The slopes of the fEPSP after $60 \mathrm{~min}(2)$ were clearly reduced compared with the fEPSPs recorded during the baseline period (1).

Calibration, $5 \mathrm{~ms}, 1 \mathrm{mV}$. the presynaptic fibre volley (Collingridge et al., 1983), an effect we did not observe with $20 \mu \mathrm{M}$ NMDA. The transient depression after iontophoretic application of NMDA was followed by a marked potentiation that declined to baseline levels within 10-30 min (Collingridge etal., 1983; Kauer etal., 1988). This discrepancy in the ability to induce LTD with NMDA can be explained by methodological differences in the concentration of NMDA used and the duration of exposure $(10 \mathrm{~s}$ vs. $3 \mathrm{~min})$. High frequency stimulation can repotentiate the synaptic signal again (data not shown; Lee etal., 1998) showing that the depression is not due to excitotoxicity. Shorter application of $20 \mu \mathrm{M}$ NMDA (1 min) or lower concentrations (5 or $10 \mu \mathrm{M}$ NMDA) (Lee etal., 1998) were not effective in inducing LTD. A longer exposure $(10 \mathrm{~min})$ to a higher concentration of NMDA $(100 \mu \mathrm{M})$ caused a $\mathrm{Ca}^{2+}$-dependent increase in cAMP, which may be important for LTP induction (Chetkovich et al., 1991).

In conclusion, our results show that $20 \mu \mathrm{M}$ NMDA applied for 3 min can elicit robust and reproducible LTD in the CA1 field of hippocampal slices from both young and adult animals. The molecular machinery underlying the induction and maintenance of chemical LTD may differ between the age groups, because chemical LTD can be blocked in slices from adult, but not from young rats, by the protein phosphatase $2 \mathrm{~B}$ inhibitor cyclosporin $\mathrm{A}$.

The decreased amount of electrical LTD observed in slices from adult rats compared with slices from young rats may probably relate 

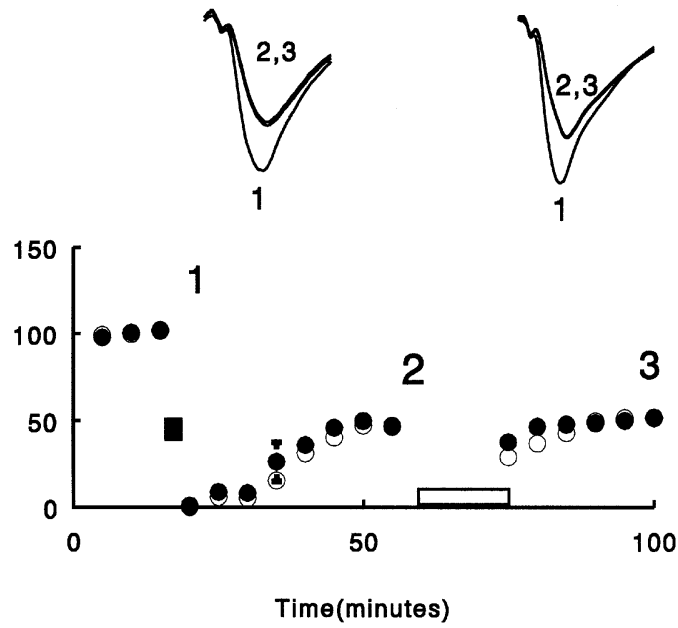

FIG. 5. Chemical LTD occludes electrical LTD in slices from young and adult rats. The effect of LFS after chemical LTD had been induced in slices from young animals (open circles) and adult animals (filled circles). The slices were first treated with $20 \mu \mathrm{M}$ NMDA for 3 min (solid bar) and the responses were recorded for $40 \mathrm{~min}$ and then received LFS ( $1 \mathrm{~Hz}$ for $15 \mathrm{~min}$, open bar) and the responses were recorded for $30 \mathrm{~min}$. The inset shows typical traces from young (left) and adult (right) animals (traces on same scale as those in Fig. 4). The numbers (1, 2 and 3 ) refer to the responses at baseline, 40 min after chemical LTD induction and $30 \mathrm{~min}$ after LFS, respectively. LFS after chemical LTD induction did not induce any further reduction in the slope of the fEPSP, showing that chemical LTD fully occluded the induction of electrical LTD. Calibration, $5 \mathrm{~ms}$ and $1 \mathrm{mV}$.

to insufficient NMDA receptor activation or reduced efficiency of intracellular cascades in slices from adult animals.

\section{Acknowledgements}

A.K. was supported by grant $96125 \mathrm{H}$ from the Dutch Diabetes Foundation and G.M.J.R. by grant 910-20-901 of MW-NWO. We would like to thank Dr M. Bear for sharing data and reading the manuscript.

\section{Abbreviations}

ACSF, artificial cerebrospinal fluid; AMPA, $\alpha$-amino-3-hydroxy-5-methyl-4isoxazolepropionic acid; AP5, D,L-2-amino-phosphonovaleric acid; DMSO, dimethylsulfoxide; fEPSP, field excitatory post synaptic potential; LFS, lowfrequency stimulation; LTD, long-term depression; LTP, long-term potentiation; NMDA, $N$-methyl-D-aspartate.

\section{References}

Bashir, Z.I. \& Collingridge, G.L. (1994) An investigation of depotentiation of long-term potentiation in the CA1 region of the hippocampus. Exp. Brain Res., 100, 437-443.

Bear, M.F. \& Malenka, R.C. (1994) Synaptic plasticity: LTP and LTD. Curr. Opin. Neurobiol., 4, 389-399.

Biessels, G.J., Kamal, A., Ramakers, G.M., Urban, I.J., Spruijt, B.M., Erkelens, D.W. \& Gispen, W.H. (1996) Place learning and hippocampal synaptic plasticity in streptozotocin-induced diabetic rats. Diabetes, 45, $1259-1266$.

Bliss, T.V. \& Collingridge, G.L. (1993) A synaptic model of memory: longterm potentaition in the hippocampus. Nature, 361, 31-39.

Chernevskaya, N.I., Obuukhov, A.G. \& Krishtal, O.A. (1991) NMDA receptor agonists selectively block $\mathrm{N}$-type calcium channels in hippocampal neurons. Nature, 349, 418-420.

Chetkovich, D.M., Gray, R., Johnston, D. \& Sweatt, J.D. (1991) $N$-methyl-Daspartate receptor activation increases cAMP levels and voltage-gated $\mathrm{Ca}^{2+}$ channel activity in area CA1 of hippocampus. Proc. Natl Acad. Sci. USA, 88, 6467-6471.

Collingridge, G.L., Kehl, S.J. \& McLennan, H. (1983) Excitatory amino acids in synaptic transmission in the Schaffer collateral-commissural pathway of the rat hippocampus. J. Physiol. (Lond)., 334, 33-46.

Connor, J.A., Wadman, W.J., Hockberger, P.E. \& Wong, R.K.S. (1988) Sustained dendritic gradients of $\mathrm{Ca}^{2+}$ induced by excitatory amino acids in CA1 hippocampal neurons. Science, 240, 649-653.

Cummings, J.A., Mulkey, R.M., Nicoll, R.A. \& Malenka, R.C. (1996) $\mathrm{Ca}^{2+}$ signalling requirements for long-term depression in the hippocampus. Neuron, 16, 825-833.

Danysz, W., Wroblewski, J.T. \& Costa, E. (1988) Learning impairment in rats by $N$-methyl-D-aspartate receptor antagonists. Neuropharmacology, 6, 653656.

Dunah, A.W., Yasuda, R.P., Wang, Y.H., Luo, J., Dávila-Arcía, M., Gbadegesin, M., Vicini, S. \& Wolfe, B.B. (1996) Regional and ontogenic expression of the NMDA receptor subunit NR2D protein in rat brain using a subunit-specific antibody. J. Neurochem., 67, 2335-2345.

Errington, M.L., Bliss, T.V., Richter-Levin, G., Yenk, K., Doyere, V. \& Laroche, S. (1995) Stimulation at $1-5 \mathrm{~Hz}$ does not produce long-term depression or depotentiation in the hippocampus of the adult rat in vivo. $J$. Neurophysiol., 74, 1793-1799.

Hansel, C., Artola, A. \& Singer, W. (1996) Different threshold levels of postsynaptic $\left[\mathrm{Ca}^{2+}\right] \mathrm{i}$ have to be reached to induce LTP and LTD in neocortical pyramidal cells. J. Physiol. (Paris), 90, 317-319.

Hansel, C., Artola, A. \& Singer, W. (1997) Relation between dendritic $\mathrm{Ca}^{2+}$ levels and the polarity of synaptic long-term modifications in rat visual cortex neurons. Eur. J. Neurosci., 9, 2309-2322.

Jarrad, L.E. (1995) What does the hippocampus really do? Behav. Brain Res., 71, 1-10.

Kamal, A., Biessels, G.J., Gispen, W.H. \& Urban, I.J. (1998) Increasing age reduces expression of LTD and dynamic range of transmission plasticity in CA1 field of the rat hippocampus. Neuroscience, 83, 707-715.

Kameyama, K., Lee, H.-K., Bear, M.F. \& Huganir, R.L. (1998) Involvement of a postsynaptic protein kinase $\mathrm{A}$ substrate in the expression of homosynaptic long-term depression. Neuron, 21, 1163-1175.

Kauer, J.A., Malenka, R.C. \& Nicoll, R.A. (1988) NMDA application potentiates synaptic transmission in the hippocampus. Nature, 334, 250252.

Kunz, J. \& Hall, M.N. (1993) Cyclosporine A, FK506 and rapamycin: more than just immunosuppression. Trends Biochem. Sci., 18, 334-338.

Lee, H.-K., Kameyama, K., Huganir, R.L. \& Bear, M.F. (1998) NMDA induces long-term synaptic depression and dephosphorylation of the GluR1 subunit of AMPA receptors in hippocampus. Neuron, 21, 1151-1162.

McHugh, T.J., Blum, K.I., Tsien, J.Z., Tonegawa, S. \& Wilson, M.A. (1996) Impaired hippocampal representation of space in CA1-specific NMDAR1 knockout mice. Cell, 87, 1339-1349.

Mondadori, C., Weiskrantz, L., Buerki, H., Petschke, F. \& Fagg, G.E. (1989) NMDA receptor antagonists can enhance or impair learning performance in animals. Exp. Brain Res., 75, 449-456.

Monyer, H., Burnashev, N., Laurie, D.J., Sakmann, B. \& Seeburg, P.H. (1994) Developmental and regional expression in the rat brain and functional properties of four NMDA receptors. Neuron, 12, 529-540.

Morris, R.G.M., Anderson, E., Lynch, G.S. \& Baudry, M. (1986) Selective impairment of learning and blockade of long-term potentiation by an $N$ methyl-D-aspartate receptor antagonist, AP5. Nature, 319, 774-776.

Mulkey, R.M., Endo, S., Shenollka, S.R. \& Malenka, R.C. (1994) Involvement of a calcineurin/inhibitor-1 phosphatase cascade in hippocampal long-term depression. Nature, 369, 486-488.

Mulkey, R.M., Herron, C.E. \& Malenka, R.C. (1993) An essential role for protein phosphatases in hippocampal long-term depression. Science, 261, $1051-1055$.

Paupard, M.C., Friedman, L.K. \& Zukin, R.S. (1997) Developmental regulation and cell-specific expression on $N$-methyl-D-aspartate receptor splice variants in rat hippocampus. Neuroscience, 79, 399-409.

Tsien, J.Z., Huerta, P.T. \& Tonegawa, S. (1996) The essential role of hippocampal CA1 NMDA receptor-dependent synaptic plasticity in spatial memory. Cell, 87, 1327-1338.

Wagner, J.J. \& Alger, B.E. (1995) GABAergic and developmental influences on homosynaptic LTD and depotentiation in rats hippocampus. J. Neurosci., 15, 1577-1586.

Watkins, J.C. \& Evans, R.H. (1981) Excitatory amino acid transmitters. Аnпи. Rev. Pharmacol. Toxicol., 21, 165-204.

Wexler, E.M. \& Stanton, P.K. (1993) Priming of homosynaptic long-term depression in hippocampus by previous activity. Neuroreport, 4, 591-594.

Wilson, M.A. \& Tonegawa, S. (1997) Synaptic plasticity,place cells and spatial memory: study with second generation knockouts. Trends Neurosci., 20, 102-106. 